\title{
An Assessment of the Public attitudes towards the Inner City of Johannesburg as a Branded Destination
}

\author{
Nikita J. C. Daya \\ Department of Marketing, University of the Witwatersrand \\ Email: nikita.daya@gmail.com \\ * Norman Chiliya \\ Department of Marketing, University of the Witwatersrand, Private Bag 3, Wits 2050 \\ Email: norman.chiliya@wits.ac.za
}

\section{Doi:10.5901/mjss.2014.v5n27p1473}

\begin{abstract}
Cities across the world have shifted their focus to urban development and place marketing strategies. These concepts are increasingly becoming important since the competition between cities have intensified globally in order to obtain investments, attract tourists, provide better living space, and to improve community businesses and overall economies of the city. Johannesburg has made use of various labels to provide a unique and attractive destination brand. The city has undergone significant changes in order to improve and reposition its image. In particular, there has been a focus on the redevelopment and brand image repositioning of the Inner City of Johannesburg. Redevelopment strategies have been outlined and implemented in order to improve the areas within the Inner City of Johannesburg. The primary purpose of this study was to investigate the effects of the current attitudes and perceptions of the public towards the Inner City of Johannesburg. A quantitative approach was used. A convenience sample consisting of 343 individuals within the Inner City of Johannesburg completed the distributed survey instrument. The data analysis consists of multiple linear regression analysis. The results of this study indicate that Government services and social bonding are the key factors the public value when they visit the inner city.
\end{abstract}

Keywords: Attitudes, Place branding and Branded Destination

\section{Introduction}

In the past, city areas were known to be the place of work and residence for the majority of city locals (Hughs, 1999). During the mid-twentieth century, numerous inner city areas have experienced a decline in population and have been abandoned (Hughs, 1999). In general, this was due to the increased and improved technologies and increased housing options in outer suburbs which enabled people to live in areas away from their workplace (Balsas, 2000). The abandoned inner city areas were left to become unsafe with limited business and leisure opportunities together with limited access (Thomas \& Bromley, 2000).

Due to these problems, cites across the world have shifted their focus to urban development strategies and place marketing strategies (McCarthy, 2002). These concepts are increasingly becoming important since the competition between cities have intensified in order to obtain investment, attract tourists, provide better living space, and to improve community businesses and overall economies of the city (Kotler \& Gertner, 2002).

In particular, the City of Johannesburg has made use of various labels and brands to market the city as whole. Johannesburg is one of six metropolitan cities in South Africa and has transformed from a mining centre and industrial city to a metropolitan centre and to financial and business services (Ahmed, 2010). The city displays specific features and has undergone significant changes and marketing labels to brand and reposition its image. This is in order to sell the city to tourists, potential investors and residents (Peyroux, 2008; Beavon, 2007). During the 19th century The City of Johannesburg used brands and labels such as "The Empire's great gold centre" and the "financial and economic hub of Sun-Saharan Africa". Johannesburg was then referred to as "little New York" and "Southern Africa's transport hub and shopping centre" in the $20^{\text {th }}$ century. The $21^{\text {st }}$ century has seen Johannesburg labelled as a "world-class city" which was transformed to "Golden Heartbeat of Africa" and most recently "World-class African City" (Walsh, 2013).

Although the City of Johannesburg has been branded through different images and labels, it is a city of vast variety 
where there are extremes of poverty in some areas and other areas are driven by success and high-class. More specifically, the Inner City of Johannesburg has experienced a period of stagnation since the end of apartheid and has had various development projects with the aims of improving the areas and its image (Dirsuweit, 1999).

City of Johannesburg \& Johannesburg Development Agency (2009) highlights some of the improvements since the implementation of redevelopment initiatives. An example is the private sector taking responsibility for the improvement, management and maintenance of public space which includes: Civic Park Braamfontein, Braamfontein streetscape, Main Street, Gandhi Square, Fox street, Fashion Square, FNB Block, ABSA Campus, Standard Band Superblock and Anglo Main Street.

Taking into account the developments that have taken place, this particular study will investigate the effects of the attitudes of the public towards the Inner City of Johannesburg as a desired destination brand. The nature of this research is descriptive and quantitative. This study is important in understanding the effectiveness of previous marketing communications of the upliftment of the Inner City of Johannesburg. This study provides an understanding of the attitudes the public have towards the Inner City of Johannesburg.

\section{Problem Definition}

For a long time, places have felt the need to differentiate themselves from each other in order to emphasise their unique attributes in search for economic, socio-psychological or political goals (Kavaratzis \& Ashworth, 2005). Destination brands have the ability to enhance the image of a place while attracting, tourists, investments and business improvements for the place (Trueman, Klemm \& Giroud, 2004). While the notion of urban branding is widespread globally, in South Africa it remains unexplored (Rogerson, 1996). There is therefore a need to contribute to place branding research in the South African context.

Although there have been improvements within the inner city of Johannesburg, there are still pertaining issues present. According to the Inner City BRT Station Precinct Analysis Market Research (2009), the following issues still remain: crime levels and lack of security; the need to upgrade areas in order to increase rentals on buildings; and the need to decrease illegal land invasion and occupation within the inner city centre areas. This presents a need to understand which factors of the Inner City are considered to be important amongst its public consumers.

The aim of the marketing and communications programmes for the Johannesburg Inner City was to create it a specific identity: "a safe, African City Centre where the arts, culture and entertainment meet thriving, business and industry" (Inner City Position Paper, 2001). Communication of city improvements and its brand is another important issue that has been recognised. Although many cities have successfully rebuilt their inner city centres, the public often is not made aware of these changes (Walle, 1993).

Ineffective communication of city improvements may cause a city to suffer from a poor brand image. Trueman, Klemm and Giroud (2004) reveal that having poor perceptions of a city further hinders the future prosperity of a city. Negative perceptions of a place may reduce future investments, is disadvantageous for attracting tourists, and it weakens business community activities of the place (Trueman et al., 2004). On the other hand, a positive city brand image reinforces improvement and development of the place. This may instil community pride and enhance economies of the city (Trueman et al., 2004). The image of a place may strongly influence the wellbeing with the satisfaction and wellbeing and satisfaction of its citizens and visitors. This indicates a need for understanding the attitudes and perceptions the public has towards a city centre brand.

\section{Research Objectives}

\subsection{Primary Objective}

Since the aim of the marketing and communications programmes for the Johannesburg Inner City is to create it a specific identity: "a safe, African City Centre where the arts, culture and entertainment meet thriving, business and industry" (Inner City Position Paper, 2001), the primary research objective of this study is to therefore investigate the current attitudes and perceptions of the public towards the Inner City of Johannesburg as a destination brand.

\subsection{Secondary Objectives}

- To identify which factors of the Inner City of Johannesburg have an effect on the attitude towards its brand; 


\section{Literature Overview}

\subsection{Place Branding}

Place branding can ultimately be defined as a way of communicating and differentiating a destination from its competitors by highlighting its unique attributes (Qu, Kim \& Im, 2011). Place branding may vary according to scale. Some concepts have focused on nation branding, urban branding, city branding, town branding and region branding (Hanna \& Rowley, 2008).

The place "product" can be described as a unique combination of buildings, venues, facilities, scenery and culture which form the basis for public and private business, residence and entertainment (Hankinson, 2009; Cakmak \& Isaac, 2012). The "consumers" of the place are those individuals who utilise the place for numerous reasons such as luxury, entertainment business or residential purposes (Qu et al., 2011).

Place branding evolved from various research fields. It has been studied extensively under tourism and has moved from tourism research to business and marketing studies (Hankinson, 2009).

\subsection{Importance of place brands}

Researching the destination brand of the inner city is of importance (Gilmore, 2007). Destination brands enhance the image amongst its residents, visitors and aids destination management organisations in measuring their goals and achievements for the destination. Enhancing the brand and image of a destination may aid in attracting investments, promote business opportunities, both local and international tourists to the area. Place brands are known to provide a positive economic impact on the area (Trueman, et al, 2004; Qu et al., 2011).

\subsection{Factors that affect place branding}

The brand of a place is affected by its perceived image (Morgan, 2003). The image of a place may be formed by personal factors and stimulus factors such as information sources, previous experience of the place, and the distribution of information. Various other factors within a destination may affect the image perceived by individuals. Some of these factors include architecture, the culture, the nature of the place, the atmosphere, the government services, the transport facilities and crime and safety levels of the place (Wang \& Fesenmaier, 2006; Wood, 2000).

Attitudes are evaluative judgements (Malhotra, 2005). These judgements may be retrieved from memory, constructed on the spot, or a combination of both. Furthermore, attitudes are evaluated according to an individual's goals and motivations which, depending on the situation, may either be temporary or enduring in nature. In addition, the process of attitude formation can occur spontaneously through perceptual heuristics and images which relate to feelings (affect) or through a deliberate process of thinking and recalling beliefs (cognition) (Argyriou \& Melewar, 2011).

Attitudes have been considered to be important especially for consumer behaviour purposes (Argyriou \& Melewar, 2011). The attitude a person holds is a function of the beliefs a person has at a given time. This allows marketers to explore the strengths and weaknesses of their brands according to relevant characteristics (Gresham, Bush \& Davis, 1984).

Attitudes are also of importance for place brands. Having a positive perception of a place brand may instil community pride and enhance the economies of the place whereas on the other hand, negative perceptions may hinder a place's prosperity by reducing future investments, reduce the number of tourists which will be disadvantageous for the business community activities of the place (Trueman et al.,2004).

Factors that influence attitude include motivation, prior knowledge, experience, and mere exposure to the object (Gresham et al., 1984). The level of experience and exposure will influence the nature of the attitude.

Merrilees, Miller and Herrington (2009) designed a brand association model that considers the different elements of a place and its effect on the attitude of the brand of that place. The brand association model incorporates the different factors into safety, cleanliness, the natural environment (scenery, atmosphere, climate), business creativity (business opportunities, business innovation), shopping facilities (fashion, home-ware, places for coffee), transport facilities, government services (healthcare, educational facilities, government initiatives), cultural activities (cultural diversity, events and festivals) social bonding (a place to socialise with friends and family), intentions to stay in the city and the overall brand attitude of that place. 


\section{Proposed Conceptual Model}

The model adopted for this study is the modified version of the brand association model by San Martin and del Bosque (2008). The elements of the model are elaborated below.

Figure 1: The Modified Brand Association Model

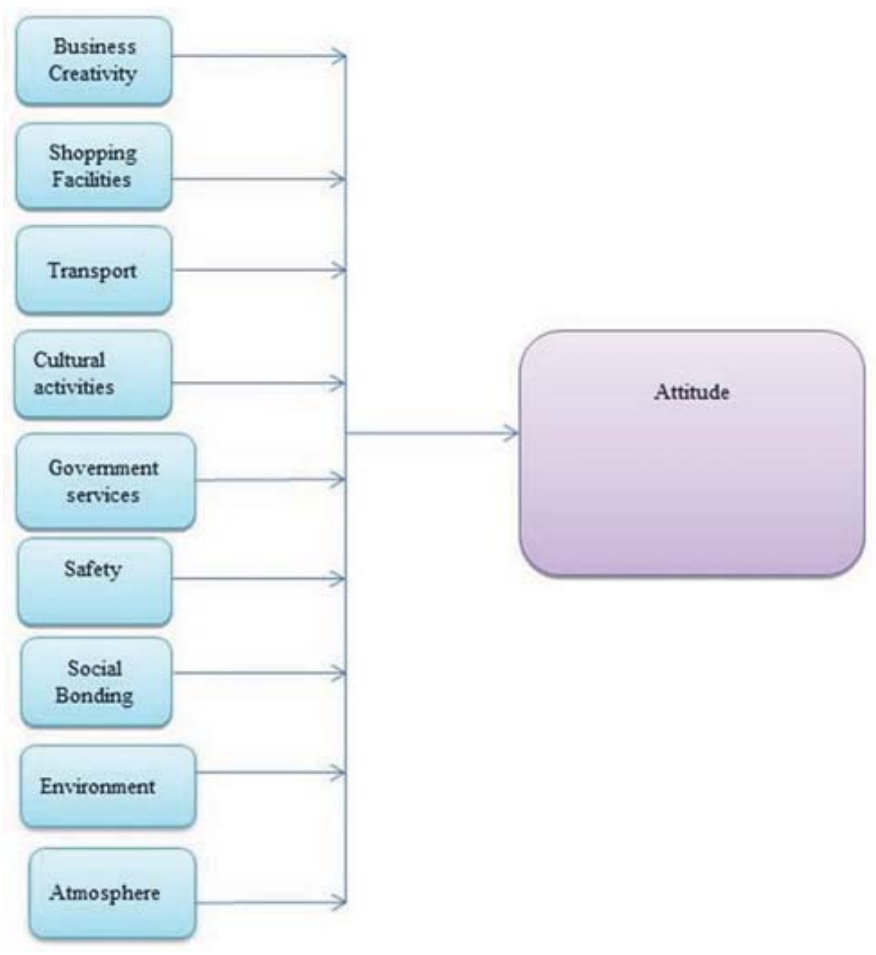

\section{Hypotheses}

$\mathrm{H}_{1}$ : The greater levels of perceived business creativity has an effect on the place brand attitudes towards the Inner City of Johannesburg.

$\mathrm{H}_{2}$ : The greater levels of perceived shopping facilities has an effect on the place brand attitudes towards the Inner City of Johannesburg.

$\mathrm{H}_{3}$ : The greater levels of perceived transportation facilities has an effect on the brand attitudes towards the Inner City of Johannesburg.

$\mathrm{H}_{4}$ : The greater levels of perceived cultural activities has an effect on brand attitudes towards the Inner City of Johannesburg.

$\mathrm{H}_{5}$ : The greater levels of perceived government services has an effect on place brand attitudes towards the Inner City of Johannesburg.

$\mathrm{H}_{6}$ : The greater levels of perceived safety has an effect on place brand attitudes towards the Inner City of Johannesburg.

$\mathrm{H}_{7}$ : The greater levels of perceived social bonding has an effect on the place brand attitudes towards the Inner City of Johannesburg.

$\mathrm{H}_{8}$ : The greater levels of the perceived environment has an effect on the place attitudes towards the Inner City of Johannesburg.

$\mathrm{H}_{9}$ : The greater levels of perceived atmosphere has an effect on the place brand attitudes towards the Inner City of Johannesburg. 


\section{Research Design and Methodology}

\subsection{Sampling Technique}

The nature of this study is descriptive and quantitative. A convenience sample of 343 individuals within the Johannesburg Inner City was obtained for this particular study. The inner city forms part of Region 8 of the City of Johnnesburg. It consists of the City Centre, the lower density predominately residential areas to the east of the City Centre consisting of Yeoville, Bertrams, Troyeville, Braamfontein, Jeppestown, the higher density suburbs of Berea and Hillbrow, and the areas of Newtown, Fordsburg and Pageview/Vredorp to the west of Newtown (Inner City Position Paper, 2011).

\subsection{Data Gathering}

A pilot study was not done since the scales were taken from sources of previous tried and tested studies. The scales for testing "affect" were taken from Beerli \& Martin (2004) and Merrliee et al. (2009). These were asked in the form of 7-likertscales where 1= strongly disagree and 7=strongly agree.

\subsection{Data Analysis}

Multiple linear regression was used to analyse the different factors that have an effect on the place brand attitude.

\subsection{Scope of the study}

Altitudes are moderated by factors such as the mood the person is in (Qu, et al., 2011). This may have had an effect on the results of the study and there is no control of this factor on attitude.

It should be noted that an individual's image formation and therefore their attitudes towards a place may be affected by prior information (primary and secondary) and other influences such as influences by friends/family. This study does not test these factors that may have influenced the attitude of the city centre of Johannesburg.

The study only focused on individuals who are in the inner city areas at the time of the questionnaires being handed out. Due to time constraints, the surveys were not handed out to other areas of Johannesburg.

\subsection{Reliability of the data}

Table 1: Reliability of Variables

\begin{tabular}{|l|c|}
\hline Variable & Cronbach Alpha \\
\hline Safety & 0.914532 \\
\hline Environment & 0.911447 \\
\hline Overall brand Attitude & 0.951029 \\
\hline Atmosphere & 0.812748 \\
\hline Business creativity & 0.820901 \\
\hline Shopping Facilities & 0.828250 \\
\hline Transport Facilities & 0.819161 \\
\hline Cultural Activities & 0.851302 \\
\hline Government Services & 0.926853 \\
\hline Social Bonding & 0.884742 \\
\hline Intentions & 0.960201 \\
\hline
\end{tabular}

The Pearson's Cronbach Alpha test was used to test the reliability of the scales used for each variable in the survey. It is generally accepted that a Cronbach Alpha above 0.6 is satisfactory for a data set (Malhotra, 2006). The above table indicates that all variables used in this research are above 0.6 and therefore have a strong reliability. This means that the scales used to test the variables of this research have been reliable.

It should be noted that the variable Atmosphere had negative outcomes due to two questions being worded in a negative manner. In order to remove the negative values reverse coding was applied to the data of the negatively asked questions. The reversed coded data has been used for all statistical analysis. 


\section{Hypotheses Testing}

The hypotheses of the study were tested at a $5 \%$ level of significance. If a p-value is smaller than the level of significance, one would reject the null hypothesis. If the p-value is larger than the level of significance, one would fail to reject the null hypothesis (Malhotra \& Peterson, 2006).

\subsection{Model:}

Model: $y_{i}=\beta_{0}+\beta_{1} X_{1}+\beta_{2} X_{2}+\beta_{3} X_{3+} \beta_{4} X_{4+} \beta_{5} X_{5}+\beta_{6} X_{6+} \beta_{7} X_{7+} \beta_{8} X_{8+} \beta_{9} X_{9}+E_{i}$

$y_{i}=$ Intercept $X_{1}+$ Atmosphere $X_{2}+$ Safety $X_{3}+$ Environment $X_{4}+$ Business Creativity $X_{5}+$ Shopping Facilities $X_{6}+$ Transport Facilities $X_{7}+$ Cultural Activities $X_{8}+$ Government Services $X_{9}+$ Social Bonding $X_{10}+E_{i}$

Since there were more than two variables that affected the variable of attitude a multiple linear regression was used to analyse the relationships between the various factors of the Inner City of Johannesburg and the attitude towards the brand of the attitude.

Multicollinearity occurs when there are variables within a regression equation are highly correlated with one another. This means that any changes in one predictor variable will cause a change in other predictor variables. Furthermore, when the correlation is removed from the equation the significance values of the coefficients will alter to a large extent (Bates \& Watts, 1998).

Multicollinearity will be present if the condition indices are above the value of 10. If multicollinearity is present then simple linear regression analysis would need to be conducted for each variable on attitude. By examining the condition indices in Table 2 it can be seen that no multicollinearity is present. The multiple linear regression analysis is therefore appropriate for this study.

Table 2: Collinearity Diagnostics

\begin{tabular}{|c|c|c|c|c|c|c|c|c|c|c|c|}
\hline \multicolumn{10}{|c|}{ Collinearity Diagnostics (intercept adjusted) } \\
\hline \multirow{2}{*}{$\#$} & Eigenvalue & $\begin{array}{c}\text { Condition } \\
\text { Index }\end{array}$ & Avatmos & Avsafety & Avenv & Avbuscreat & Avshopfac & Avtransfac & Avgovserv & Avcultact & Avcosbond \\
\hline 1 & 3.33458 & 1.0000 & 0.02456 & 0.00751 & 0.00786 & 0.02583 & 0.02607 & 0.02212 & 0.02697 & 0.02788 & 0.02898 \\
\hline 2 & 1.26205 & 1.6254 & 0.07271 & 0.22763 & 0.24616 & 0.01578 & 0.03066 & 0.02340 & 0.00809 & 0.00785 & 0.00114 \\
\hline 3 & 0.80876 & 2.0305 & 0.02128 & 0.06083 & 0.14020 & 0.13772 & 0.04255 & 0.36214 & 0.13304 & 0.000434 & 0.00928 \\
\hline 4 & 0.80473 & 2.0356 & 0.01875 & 0.54252 & 0.31095 & 0.05664 & 0.00017 & 0.09822 & 0.00516 & 0.00210 & 0.00554 \\
\hline 5 & 0.73542 & 2.1293 & 0.01903 & 0.00512 & 0.01180 & 0.00355 & 0.12087 & 0.24217 & 0.20989 & 0.32803 & 0.000018 \\
\hline 6 & 0.63061 & 2.2995 & 0.00277 & 0.03509 & 0.00405 & 0.24488 & 0.00194 & 0.00637 & 0.17465 & 0.06451 & 0.47398 \\
\hline 7 & 0.54078 & 2.4831 & 0.60411 & 0.08895 & 0.24203 & 0.00022 & 0.24250 & 0.05375 & 0.01296 & 0.00339 & 0.000002 \\
\hline 8 & 0.53004 & 2.5082 & 0.02515 & 0.02161 & 0.01387 & 0.02759 & 0.00230 & 0.13251 & 0.41030 & 0.49957 & 0.16335 \\
\hline 9 & 0.35303 & 3.0733 & 0.21165 & 0.01073 & 0.02308 & 0.48780 & 0.53295 & 0.05932 & 0.01894 & 0.06624 & 0.31771 \\
\hline
\end{tabular}

Table 3: Multiple Linear Regression

\begin{tabular}{|c|c|c|c|c|c|}
\hline \multicolumn{7}{|c|}{ Analysis of Variance } \\
\hline Source & DF & $\begin{array}{c}\text { Sum of } \\
\text { Squares }\end{array}$ & $\begin{array}{c}\text { Mean } \\
\text { Square }\end{array}$ & F Value & Pr > F \\
\hline Model & 9 & 270.55467 & 30.06163 & 33.63 & $<.0001$ \\
\hline Error & 306 & 273.49921 & 0.89379 & & \\
\hline Corrected Total & 315 & 544.05389 & & & \\
\hline \multicolumn{7}{|c|}{} & R-Square & 0.4973 \\
\hline \multicolumn{7}{|c|}{ Root MSE } & 0.94540 & Adjusted R-Square & 0.4825 \\
\hline Dependent Mean & 3.11656 & & \\
\hline Coefficient Variance & 30.33484 & & \\
\hline
\end{tabular}




\begin{tabular}{|c|c|c|c|c|c|}
\hline \multicolumn{6}{|c|}{ Parameter Estimates } \\
\hline Variable & DF & $\begin{array}{l}\text { Parameter } \\
\text { Estimate }\end{array}$ & $\begin{array}{l}\text { Standard } \\
\text { Error }\end{array}$ & $\mathrm{t}$ Value & $\operatorname{Pr}>|t|$ \\
\hline Intercept & 1 & -2.21500 & 0.49678 & -4.46 & $<.0001$ \\
\hline Atmosphere & 1 & 0.36698 & 0.10813 & 3.39 & 0.0008 \\
\hline Safety & 1 & 0.05663 & 0.04497 & 1.26 & 0.2089 \\
\hline Environment & 1 & 0.14296 & 0.04757 & 3.01 & 0.0029 \\
\hline Business Creativity & 1 & -0.04205 & 0.05905 & -0.71 & 0.4769 \\
\hline Shopping Facilities & 1 & 0.09772 & 0.05733 & 1.70 & 0.0893 \\
\hline Transport Facilities & 1 & -0.02752 & 0.05300 & -0.52 & 0.6039 \\
\hline Government Services & 1 & 0.24610 & 0.06162 & 3.99 & $<.0001$ \\
\hline Cultural Activities & 1 & 0.11310 & 0.05888 & 1.92 & 0.0557 \\
\hline Social Bonding & 1 & 0.40335 & 0.05312 & 7.59 & $<.0001$ \\
\hline Number of Observations Read & 316 & & & & \\
\hline Number of Observations Used & 316 & & & & \\
\hline
\end{tabular}

The results indicate that there are seven insignificant variables: Atmosphere, Safety, Environment, Business Creativity, Shopping Facilities, Transport Facilities and Cultural Activities. $\mathrm{H}_{1}, \mathrm{H}_{2}, \mathrm{H}_{3}, \mathrm{H}_{4}, \mathrm{H}_{5}, \mathrm{H}_{6}$ and $\mathrm{H}_{8}$ were rejected. This means that government services and social services are the significant factors that have an effect on the brand attitude of the Inner City of Johannesburg.

It should be noted that these results differ with those obtained in the research of Merrillees et al., (2009) which explored the antecedents of place brand attitudes of the Gold Coast City in Australia. The findings of this previous study indicate that safety, business creativity, and the natural environment had a major effect on the place brand attitudes of that city. Although this is the case, it has been noted that each city or place is likely to have a dominant distinct feature and this may vary from one place to another (Morgan, 2004).

\section{Discussion of Results}

\subsection{Government Services in the Inner City of Johannesburg}

There are negative attitudes towards the government services in that individuals have a perception that there is no access to good healthcare, there are not many educational facilities, and that the needs of the elderly are catered for in the areas of the Inner City of Johannesburg. Furthermore the negative perceptions may be attributed to respondents not being pleased with the council's services and not trusting the government to make sound decisions regarding the Inner City of Johannesburg. Development initiatives would need to measure the level of standard of government services and improvements would need to be implemented if required to do so. In order to alleviate the negative perceptions, marketers would need to highlight improvements made. This can only be done once the implementation of the improved government services has been successful.

\subsection{Social Bonding}

There are negative perceptions of the Inner City of Johannesburg as a place where people can meet and bond. This indicates that individuals are not proud of the Inner City of Johannesburg. Furthermore, individuals within the Inner City do not believe that the Inner City has a good reputation that has a good lifestyle. This indicates that they would prefer being in other areas rather than the Inner City of Johannesburg.

\section{Limitations}

Attitudes are moderated by factors such as the mood the person is in (Qu, et al., 2011). This may have had an effect on the results of the study and there is no control of this factor on attitude.

It should be noted that an individual's image formation and therefore their attitudes towards a place may be affected by prior information (primary and secondary) and other influences such as influences by friends/family. This study does not test these factors that may have influenced the attitude of the city centre of Johannesburg.

The study only focuses on individuals who are in the inner city areas at the time of the questionnaires being 
handed out. Due to time constraints, the survey was not distributed to other areas of Johannesburg. Future research should consider making a comparative analysis of attitudes of individuals between different areas within Johannesburg and the Inner City of Johannesburg.

A major limitation to this study is the language barrier between the research instrument used and the respondents. Since the Inner City of Johannesburg is a diverse place, there were areas where individuals do not understand English. Low-skilled workers and residents in areas such as Berea and Hillbrow were found to not have a complete understanding of English. This may be due to cultural and educational backgrounds. Respondents who could clearly understand English were only able to participate in this study. The data and results may therefore be slightly skewed according to respondents who understand English. Future research should consider having an instrument that may be in different languages found within the Inner City of Johannesburg.

This was a broad study and considered all types of possible "consumers" within the Inner City of Johannesburg. Future research should consider a focus on each of the different types of consumers such as individuals who use the Inner City for residence, workplace, shopping, tourism, culture, entertainment purposes etc.

This study focuses on attitudes at a specific time. Attitudes are constantly changing and future research should therefore consider studying the attitudes of individuals over a period of time. It should be noted that redevelopment initiatives at this point in time are still underway and the process has not been completed. This may have affected the results of the effects of the attitudes on the brand of the Inner City of Johannesburg.

\section{Conclusion}

Inner City of Johannesburg has experienced a period of stagnation since the end of apartheid and has had various development projects with the aims of improving the areas and its image (Dirsuweit, 1999). In order to uplift the Inner City of Johannesburg a vision for the Inner City of Johannesburg was put forward and since then redevelopment initiatives have been implemented. The primary the primary research objective of this study is to understand the current attitudes and perceptions of the public towards the Inner City of Johannesburg as a destination brand and its effect on consumer intentions. In this study it was identified that negative attitudes towards the brand are present and therefore individuals are reluctant to consider residing in the Inner City of Johannesburg.

It has further been observed that government services and the social bonding factors have a significant effect on the brand attitude towards the Inner City of Johannesburg. The aim of the marketing and communications programmes for the Johannesburg Inner City is to create it a specific identity: "a safe, African City Centre where the arts, culture and entertainment meet thriving, business and industry". The results indicate that the Inner City of Johannesburg lacks positive perceptions and therefore the perceptions do not coincide with vision and marketing communication aims.

Several limitations of this study have been outlined together with possible future research approaches to this topic. This research study provides an understanding of the current attitudes and intentions of the public towards the Inner City of Johannesburg. This research further provides marketing implications that coincide with redevelopment initiatives.

\section{References}

Ahmed, P. (2010). Inner City Nodes and public transportation networks: Location, linkages and dependencies of the urban poor within Johannesburg HIS Working Papers, 26.

Argyriou , E., \& Melewar, T.C. (2011). Consumer Attitudes Revisited: A review of Attitude Theory in Marketing Research, International Journal of Management Reviews, 13, 431-451

Balsas, C. J. L. (2000). City Centre Revitalisation in Portugal, lessons from two medium sized cities. Cities, 17(1), 19-31.

Bates. D.M \& Watts.D.G. (1988). Nonlinear Regression Analysis and Its Applications. Wiley. New York.

Beavon, K. (2007). The making of Johannesburg: The making and Shaping of the City Journal of Southern African Studies, 33(1), 219221.

Bromley, R. D. F., Tallon, A. T. \& Thomas, C. J. (2005) City centre regeneration through residential development: contributing to sustainability, Urban Studies, 42(13), pp. 2407-2429.

Cakmak, E., \& Isaac, R. K. (2012). What destination marketers can learn from their visitors' blogs Journal of Destination Marketing and Management, 1, $124-133$

Dirsumeit, T. (1999). From Fortress City to Creative City Urban Forum, 10(2),183-213.

City of Johannesburg \& Johannesburg Development Agency (2009). Inner City BRT Station Precinct Analysis Market Research, retrieved from http://www.joburg-archive.co.za/2011/inner_city/brt/cover.pdf 12.May 2014

Gilmore, F. (2002). A Country - Can it be repositioned? Spain - The success story of country branding, Brand Management, 9(4-5), 281-293.

Gresham, L.G., Bush, A.J., \& Davis, R.A. (1984). Measure of brand attitude: are cognitive structure approaches really needed? Journal 
of Business Research, 12, 353-361.

Hanna, S., \& Rowley, J. (2008). An analysis of terminology use in place branding Place Branding and Public Diplomacy, 4, 61-75.

Hankinson, G. (2009). Managing destination brands: establishing a theoretical framework, Journal of Marketing Management, 25(1-2), 97-115.

Hughs, G. (1999). Urban Revitalisation: the use of festive time strategies Leisure Studies, 18(2), 119 - 135.

Inner City Position Paper (2001). Retrieved from http://www.jda.org.za/key docs/inner_city_position_paper_jan2001.pdf. 12.May.2014.

Kavaratzis, M. \& Ashworth, G. (2005). City branding: An affective assertion of identity or a transitory marketing trick Tijdschrift voor Economische en Sociale Geografie, 96(5), 506-614.

Kotler, P. \& Gertner, D. (2002). Country as a brand, product and beyond: A place marketing and brand management perspective Journal of Brand Management, 9(4), 249-261.

Malhotra, N. K., \& Agarwal, J. (2005). A integrated model of attitude and affect: Theoretical foundation and empirical investigation, Journal of Business Research, 58, 483-493.

Malhotra, N. \& Peterson, M., 2006. Basic Marketing Research: a Decision-Making approach, second edition. New Jersey: Pearson Prentice Hall.

McCarthy, J. (2002). Entertainment-led Regeneration: the case of Detroit Cities, 19(2), 105-111.

Merrilees, B., Miller, D., \& Herington, C. (2013). City Branding: A facilitating framework for stressed satellite cities, Journal of Business Research, 66, 37-44.

Morgan, N. (2003). Destination branding and role of stakeholders, Journal of Vacation Marketing, 9(3), 285-299.

Peyroux, E. (2009). City Improvements Districts and the Production of Urban Space in Johannesburg TRIALOG, 89.

Qu, Kim \& Im (2011). A model of destination branding: Integrating the concepts of the branding and destination image Tourism Management, 32,465-475

Rogerson, C.M. (1996). Image Enhancement and Local Economic Development in Johannesburg Urban Forum, 7(2), $139-158$.

San Martin,H \& del Bosque.I.A.R (2008).Exploring the cognitive-affective nature of destination image and the role of psychological factors in its formation. Tourism Management, 29 (2) (2008), 263-277.

Thomas, C. J., \& Bromley, D. F (2000). City-centre revitalisation: Problems of Fragmentation and Fear in the Evening and Night-time City Urban Studies, 37(8), 1403-1429.

Trueman, M. M., Klemm, M. \& Giroud, A. (2004). Can a City Communicate? Bradford as a Corporate Brand Corporate Communications: An International Journal, 9(4), 317-330.

Walle, A. H. (1993). Folk Festivals are an overlooked marketing tool Marketing News, 12.

Walsh, S. (2013). We won't move: The suburbs take back the center in urban Johannesburg, City: analysis of urban trends, culture, theory, policy, action City, 17(3), 400-408.

Wang, Y. \& Fesenmaier, D. (2006). Collaborative destination marketing: A case study of Elkhart County, Indiana Tourism Management, 28(3), 863-875.

Wood, L. (2000). Brands and brand equity: Definition and management Management Decision, 38(9), 662-669. 